\title{
Akardiyak İkiz: İki Farklı Olgu İki Farklı Prognoz
}

\author{
Talat Umut Kutlu Dilek ${ }^{1}$, Güngör Gonca Yıldırım²®, Savaş Gündoğan'®
}

${ }^{1}$ Acıbedem Üniversitesi, Kadın Hastalıkları ve Doğum Anabilim Dalı, İstanbul, Türkiye

${ }^{2}$ Acıbadem Üniversitesi Atakent Hastanesi, Yüksek Riskli Gebelikler Hemşiresi, İstanbul, Türkiye

Talat Umut Kutlu Dilek, Prof. Dr. Güngör Gonca Yıldırım, Perinatoloji Hemş. Savaş Gündoğan, Dr.

Iletişim:

Dr. Savaş Gündoğan

Acıbedem Üniversitesi, Kadın Hastalıkları ve Doğum Anabilim Dalı, İstanbul, Türkiye Tel: +905064082587

E-Posta: savas483@hotmail.com
Gönderilme Tarihi : 17 Mayıs 2017

Revizyon Tarihi : 17 Mayıs 2017

Kabul Tarihi : 27 Ağustos 2017

\section{ÖZET}

Akardiyak ikiz gebelik, monokoryonik ikiz gebeliklerin \%1,46'sında izlenen nadir bir komplikasyondur(1). Kalp ve genellikle üst ekstremite dahil gövdenin üst bölümü gelişmemiş olan ikiz eşi, sağlam görünümlü ikiz eşinin umbilikal arterinden aldığı bir anastomoz ile beslenir (2). Çoğu zaman 1. trimester sonlarında tanı alabilen bu komplikasyonda, dolaşımlar arasındaki anastomotik bağlantı zamanında ayrılmaz ise pompa görevi gören sağIıklı ikiz eşi için mortalite \%55'lere ulaştığı gibi preterm doğum gibi obstetrik sorunlar da artmaktadır (3). Akardiyak ikiz eşi için mortalite kaçınılmazdır. Bu yüzden akardiyak ikiz eşinin dolaşımının durdurulması çoğu vakada sağlıklı görünen fetusun kaybı ve preterm doğum gibi sorunların önlenmesinde temel yaklaşımdır (3). Bu olgu sunumunda 11. gebelik haftasında tanı alan ancak prognozu tamamı ile farklı olan 2 TRAP (Twin Reversed Arterial Transfusion) olgusu ve klinik yönetimlerini tartışmayı amaçladık.

Anahtar sözcükler: Akardiyak, ikiz, gebelik, TRAP, monokoryonik

\section{A-CARDIAC TWIN: TWO DIFFERENT CASES AND TWO DIFFERENT PROGNOSIS}

\section{ABSTRACT}

A-cardiac twin pregnancy is a rare complication occurs in $1,46 \%$ of all monochorionic twin pregnancies. The fetus whose heart and upper body haven't been developed and the rest of the body has its blood supply from a branch of the umbilical artery can be considered a healthy fetus?!. Usually the complication can be diagnosed in the end of 1st trimester and if the anastomosis of circulation isn't separated on time, the mortality rate for the healthy fetus who has the blood pumper role will be $55 \%$. So the obstetric problems such as preterm delivery increase. The death for the fetus who has no heart is certain. Therefore, stopping the blood circulation of the fetus with cardiac abnormality is the main approach to prevent problems such as the lose of the healthy fetus and preterm delivery. We aim to discuss the clinical management of two cases which have been diagnosed with TRAP (Twin Reversed Arterial Transfusion) in their 11th week of gestation and have had totally different prognosis.

Keywords: A-cardiac, twin, pregnancy, TRAP, monochorionics

\section{Olgu 1}

Son adet tarihine göre 11 hafta 2 günlük ilk gebeliği olan hasta, rutin obstetrik muayene için geldiğinde CRL: 41,7 mm, NT: 4,2 mm olan tek canlı fetus'a komşu 22x11 $\mathrm{mm}$ boyutunda amorf, kardiyak aktivitesi olmayan akardiyak ikiz eşi izlendi. Hasta 1 hafta sonra kontrole geldiğinde, CRL: 51,56 mm, NT: 5,15 mm, yaygın cilt ödemi, VSD (Ventrikülerseptaldefekt) saptandı, hastaya koryonvillüs örneklenmesi planlandı, işlem için 3 gün sonra geldiğinde kardiyak aktivitenin olmadığı izlendi. Fetal kardiyak aktivitenin izlenmemesi ise üzerine gebelik sonlandırıldı. 

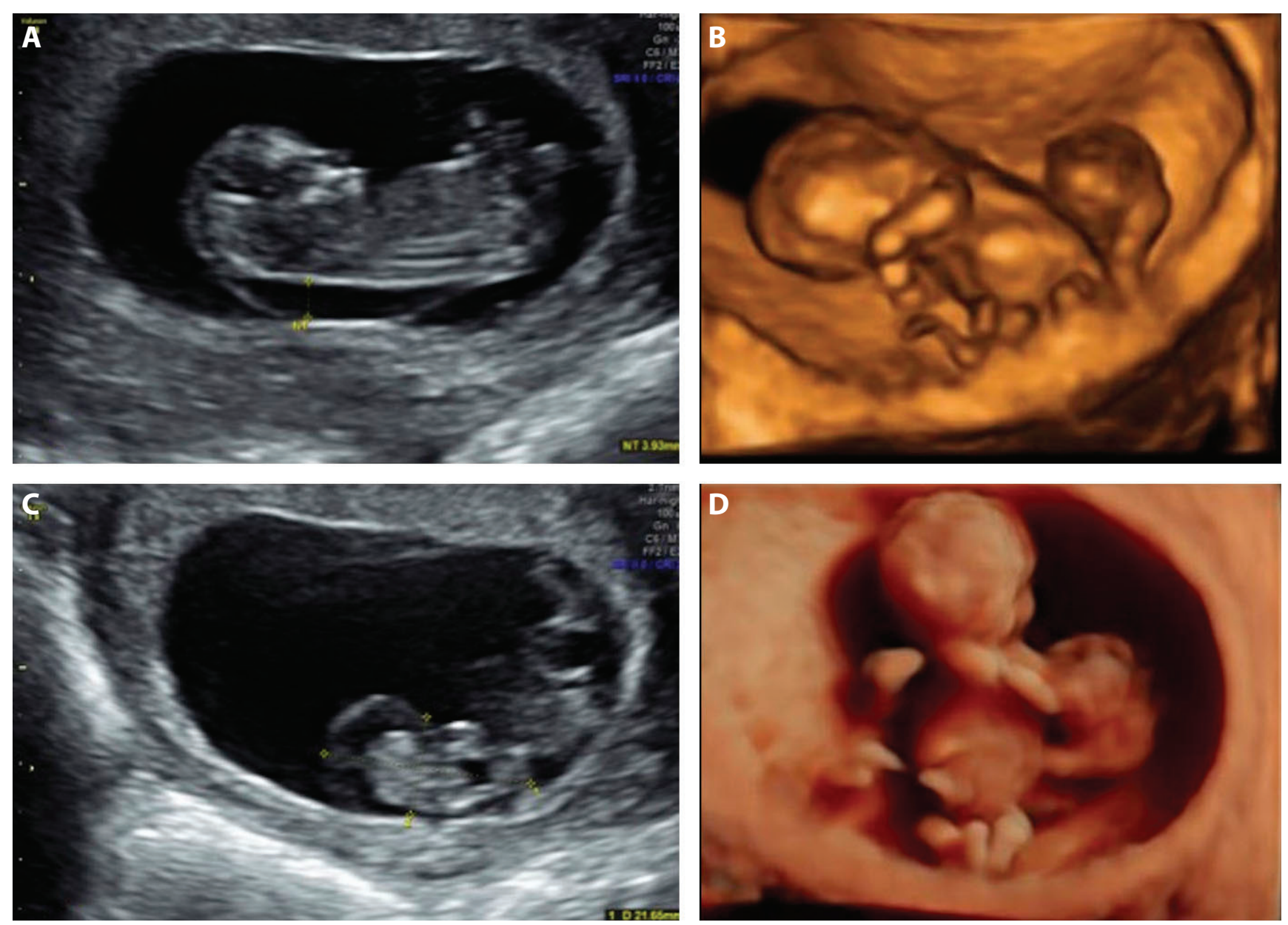

Şekil 1. 1. Olgu 11 hafta 3 gün iken,1A) 1. Olgu: normal fenotipteki fetüs için NT:3,93mm ölçülmüş, 1B, 1D) 1. Olgu: Akardiyak ikizlerin 3D görünüşü. 1C) Akardiyak ikiz eş 21,65x10,26mm olarak ölçülmüş.

\section{Olgu 2}

30 yaşında ikinci gebeliği olan hasta 10 hafta 4 günlük gebe iken rutin muayeneye geldi. Yapılan ultrasonografide CRL $37 \mathrm{~mm} 10$ hafta 4 günle uyumlu canlı fetus izlendi. Bu zamana kadar gebelik takiplerinde tek canlı olarak embriyo olarak izlenmişken hemen altında 14,43 mm uzunluğunda amorf, kardiyak aktivitesi izlenmeyen ancak hareketli ikiz eşi gözlendi. Monokoryonik diamniyotik olarak değerlendirilen ikiz gebelikte alttaki fetusun kord girişinde arteriyel akım izlendi. 12 hafta iken yapılan kontrol muayenesinde, üstteki normal görünümlü fetus CRL: 54,7 mm, NT: 1,51 mm, nazal kemik 2,39 mm, ductus venosus'da $A$ dalgası var ve $\mathrm{Pl}: 1,06$, triküspit kapakta kaçak izlenmedi. IT: 1,73 mm olup gross fetal anomali izlenmedi. Akardiyak ikiz ise $28 \mathrm{~mm}$, kordda kan akımı müspetti. Bu bulgularla monokoryonik diamniyotik ikiz gebelik ile beraber akardiyak ikiz eşi düşünülen hasta, radyofrekans veya lazer ile kordablasyonu amacıyla refere edildi. 14 . haftada yapılan muayenede CRL 83,3 mm, 14 hafta 1 gün ile uyumlu ikiz eşi izlendi. NT: 1,9 mm, nazal kemik mevcut,
IT: 2,4 mm, fetal kalp hızı 163/dk, ductus venosusda A dalgası olmakla beraber PI: 1,36'a yükselmeye başladığı görüldü. Akardiyak ikizin boyutlarının 38×20 mm olduğu, kraniyumun gelişmediği, kardiyak aktivitesinin olmadığı, alt ekstremitelerin gelişmiş, omfalosel ve kistikhigroma benzeri yaygın vücut ödeminin olduğu izlendi. Hastaya önce koryonvillüs örneklemesi yapıldı, sonucun normal konstitüsyonel karyotip gelmesi üzerine 16. gebelik haftasında önce lazer, lazer uygulamasının başarısız olması üzerine ve akardiyak ikiz eşinin toplam hacminin sağlam fetusun hacminin \%91'ine ulaşması üzerine ultrasonografi eşliğinde radyofrekans ile ablasyon işlemi uygulandı. Bütün bu işlemler sonrasında, sağ kalan ikiz eşinin 20. gebelik haftasından doğuma kadar olan takipleri normaldi. Herhangi bir kalp yetmezliği bulgusu, preterm doğum eylemi veya membran rüptürü, kanama gibi bir problem ile karşılaşılmadı. Olgu düzeltilmiş son adet tarihine göre 39 hafta 2 günlük gebe iken erken membran rüptürü ile başvurdu. $3255 \mathrm{~g} 50 \mathrm{~cm}$ kı bebek spontan vajinal yolla doğurtuldu ve komplikasyon izlenmedi. 

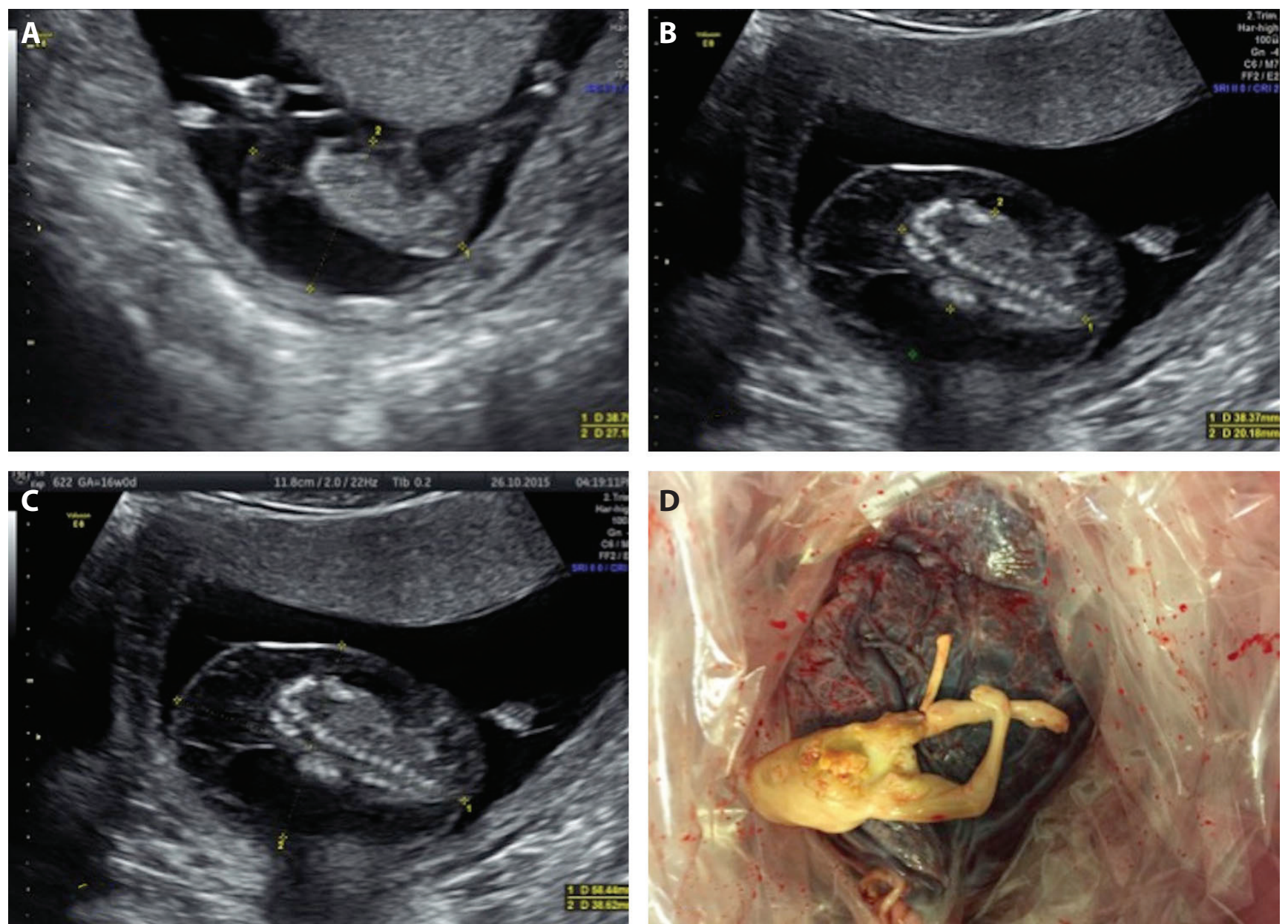

Şekil 2: 2. Olgu, 2A) 14 hafta iken akardiyak ikizin ölçüleri. 2B, 2C) 16 hafta iken akardiyak ikizin ölçüleri. 2D) Doğum sonrası akardiyak ikizin görünüşü

\section{Tartışma}

Akardiyak ikiz gebelik, monokoryonik ikiz gebeliklerin \%1'inde ve 35 bin doğumda bir izlenen bir komplikasyondur (3). Sağlam görünümlü ikiz eşi pompa ikiz eşi olarak adlandırılır ve \%20'sinde konjenital anomaliler izlenebilir. Aradaki dolaşımsal bağlantının ortadan kaldııımadığı durumlarda pompa ikiz eşinin sağ kalımı sadece \%55'dir. İlk trimesterde tanı alan 26 olguluk seride, akardiyak ikiz olgularının üçte biri, ikinci trimesterde planlanan müdahaleye kadar olan dönemde kaybedilmiş, \%21'inde (5/24) spontan olarak akım durmuş \%46'sında ise (11/24) ise 16 -18 haftada akardiyak fetusa akım devam etmiş (3). Akardiyak ikiz eşinin, sağlam görünümlü verici fetusun \%70'inden büyük olduğu durumlarda, kalp yetmezliği tablosunun geliştiği ve polihidramniyozun ortaya çıktığı vakalarda prognoz kötüdür. Illk olgumuzda yukarıda tarif edilen tablo çok kısa sürede ortaya çıkmış ve ilk tanıdan itibaren 2 hafta içinde verici ikiz kaybedilmiştir. Aradaki dolaşımsal bağlantıyı ortadan kaldırmak amacıyla akardiyak ikiz eşine intrafetal alkol uygulaması, amniyodrenaj lazer, bipolar forseps, radyofrekans ve histoacryl gibi sklerozan doku yapıştırıcıları uygulama gibi tekniklerle pompa ikiz eşi ile arasında vasküler bağlantı ortadan kaldırılmaya çalışılmıştır (4-9). Bütün bu yöntemlerde hedeflenen pompa ikizin umbilikal arteri ile akradiyak ikizin kordu arasındaki vasküler şantı ortadan kaldırmaktır. İdeal uygulama zamanı tartışmalı olmakla beraber 2. trimester olarak gözükmekte ve akardiyak ikizin boyutunun pompa ikizin \%50'sini geçtiği durumlarda vasküler oklüzyonun gerçekleştirilmesi önerilmektedir. Quintero ve arkadaşları, oklüzyon yapılan ve yapılmayan gruplarda perinatal sağ kalım oranını sırasıyla $\% 64,7$ ve 42,9 olarak bildirmişlerdir. Hescher ve arkadaşlarının 60 vakalık serisinde ortalama uygulama haftası 18,3 hafta, $\% 80$ sağ kalım ve 36 haftadan daha uzun süren gebelik oranı $\% 67,34$ haftadan önce erken membranrüptür oranı \%18 idi $(10,11)$. Akardiyak ikiz eşinde gerek kordoklüzyonu gerekse intrafetal uygulamaların zamanlaması konusunda kesin bir konsensus yoktur. Erken ikinci trimesterde bipolar forseps ile yapılan kordoklüzyonlarında, fetal ölüm \%41 iken 18. haftada yapılan işlemlerde bu oran \%3'e düşmektedir (12). Güven ve arkadaşları 
ultrasonografi eşliğinde intrafetal alkol uygulayarak 14. gebelik haftasında yaptıkları ablasyon işlem sonrası pompa ikiz eşinde miadında canlı doğum bildirmişlerdir (13). Bizim olgumuzda ilk yapılan lazer işleminin başarısız olması üzerine 18. haftada radyo frekans ablasyon işlemi uygulandı. Kuzey Amerika'da 1998-2008 yılları arasındaki TRAP nedeni ile akardiyak ikiz eşine radyofrekans ablasyon işlemi yapılan 98 olgunun sonuçları değerlendirildiğinde, $\% 80$ sağkalım ve medyan 37. haftada doğumun gerçekleştiğini bildirilmiştir (14). Bizim olgumuzda doğum eylemi 39. gebelik haftasında spontan olarak başlamıştır.

\section{Kaynaklar}

1. Hartge DR, Weichert J. Prenatal diagnosis and outcome of multiple pregnancies with reversed arterial perfusion (TRAP-sequence). Arch Gynecol Obstet 2012;286:81-8. [CrossRef]

2. Moore TR, Gale S, Benirschke K. Perinatal outcome of forty nine pregnancies complicated by a cardiac twinning. Am J Obstet Gynecol 1990;163:907-12. [CrossRef]

3. Lewi L, Valencia C, Gonzales E, Deprest J, Nikolaides KH. The outcome of twin reversed arterial perfusion sequence diagnosed in the first trimester. Am J Obstet Gynecol 2010;203:213.e1-4. [CrossRef]

4. Sepulveda W, Sfeir D, Reyes M, Martinez J. Severe polyhydramnios in twin reversed arterial perfusion sequence: successful management with intrafetal alcohol ablation of a cardiac twin and amnio drainage. Ultrasound Obstet Gynecol 2000;16:260-3. [CrossRef]

5. Weisz B, Peltz R, Chayen B, Oren M, Zalel Y, Achiron R, Lipitz S. Tailored management of twin reversed arterial perfusion (TRAP) sequence. Ultrasound Obstet Gynecol 2004;23:451-5. [CrossRef]

6. Hecher K, Lewi L, Gratacos E, Huber A, Ville Y, Deprest J. Twin reversed arterial perfusion: Fetoscopic laser coagulation of placental anastomoses or the umbilical cord. Ultrasound Obstet Gynecol 2006;28:688-91. [CrossRef]

7. Gallot D, Laurichesse $H$, Lemery D. Selective feticide in monochorionic twin pregnancies by ultrasound-guided umbilical cord occlusion. Ultrasound Obstet Gynecol 2003;22:484-8. [CrossRef]
Illk trimester sonunda monokoryonik ikiz gebelik olduğu belirlenen ve akardiyak ikiz eşi olduğu saptanan 2 olgudan biri fetal kayıp ile diğeri ise başarılı bir intrauterin fetal tedavi ile miada kadar ulaşarak doğumla sonuçlanmıştır. İlk olgu daha ilk tanı aldığı anda kötü prognoz kriterlerini taşımaktaydı. İkinci olgu ise 16. gebelik haftasına kadar spontan izlendi, ancak akardiyak ikiz eşinin giderek boyutlarının artması üzerine tedavi kararı alındı. Sonuç olarak fetuslardan birinin geç ortaya çıktığı monokoryonik ikiz gebelik olgularında her zaman akardiyak ikiz olasılığı akılda tutulmalıdır.

8. Hirose M, Murata A, Kita N, Aotani H, Takebayashi K, Noda Y. Successful intrauterine treatment with radiofrequency ablation in a case of a cradiac twin pregnancy complicated with a hydropic pump twin. Ultrasound Obstet Gynecol 2004;23:509-12. [CrossRef]

9. Ferianec V, Redecha M, Papcun P, Krizko M, Holly I, Holoman K. Successful ablation of a cardiac twin with histoacryl. Taiwanese J Obstet Gynecol 2016;55:109-11. [CrossRef]

10. Quintero RA, Chmait RH, Murakoshi T, Pankrac Z, Swiatkowska M, Bornick PW, Allen MH. Surgical management of twin reversed arterial perfusion sequence. Am J Obstet Gynecol 2006;194:982-91. [CrossRef]

11. Hecher K, Lewi L, Gratacos E, Huber A, Ville Y, Deprest J. Twin reversed arterial perfusion: Fetoscopic laser coagulation of placental anastomoses or the umbilical cord. Ultrasound Obstet Gynecol 2006;28:688-91. [CrossRef]

12. Robyr R, Yamamato $M$, Ville $Y$. Selective feticide in complicated monochorionic twin pregnancies using ultrasound-guided bipolar cord coagulation. BJOG 2005;112:1344-8. [CrossRef]

13. Guven MA, Koc O, Bodur H, Erkanlı S, Bagis T, Usal D. Acardiac twin pregnancy: successful intrauterine ablative treatment with alcohol at 14 weeks of gestation. Clin Exp Obstet Gynecol 2016;43:460-2.

14. Lee $\mathrm{H}$, Bebbington $\mathrm{M}$, Crombleholme TM; North American Fetal Therapy Network. The North America Fetal Therapy Network Registry data on outcomes of radiofrequency ablation for twin reversed arterial perfusion sequence. Fetal Diagn Ther 2013;33:2249. [CrossRef] 